\title{
The Design Parameters for the MICE Tracker Solenoid*
}

\author{
M. A. Green, C. Y. Chen, T Juang, W. Lau, C. Taylor, S. P. Virostek, R. Wahrer, S. T. Wang,
} H. Witte, and S. Q. Yang

\begin{abstract}
The first superconducting magnets to be installed in the muon ionization cooling experiment (MICE) will be the tracker solenoids. The tracker solenoid module is a five coil superconducting solenoid with a $400 \mathrm{~mm}$ diameter warm bore that is used to provide a $4 \mathrm{~T}$ magnetic field for the experiment tracker module. Three of the coils are used to produce a uniform field (up to $4 \mathrm{~T}$ with better than 1 percent uniformity) in a region that is $300 \mathrm{~mm}$ in diameter and $1000 \mathrm{~mm}$ long. The other two coils are used to match the muon beam into the MICE cooling channel. Two 2.94-meter long superconducting tracker solenoid modules have been ordered for MICE. The tracker solenoid will be cooled using two-coolers that produce $1.5 \mathrm{~W}$ each at $4.2 \mathrm{~K}$. The magnet system is described. The decisions that drive the magnet design will be discussed in this report.
\end{abstract}

Index Terms-Superconducting Solenoids, and Muon Cooling

\section{INTRODUCTION}

$\mathrm{T}_{\mathrm{r}}^{\mathrm{h}}$ he development of a muon collider or a neutrino factory requires that beams of low emittance muons be produced. A key to the production of low emittance muons is muon ionization cooling. A demonstration of muon cooling is essential to the development of muon accelerators and storage rings [1]. The international Muon Ionization Cooling Experiment (MICE) will be a demonstration of muon cooling in a configuration of superconducting magnets [2] and absorbers that may be useful for a neutrino factory.

Ionization cooling of muons means that muons have their momentum reduced in both the longitudinal direction and the transverse direction by passing them through a low $\mathrm{Z}$ absorber (such as liquid hydrogen). RF cavities are used to re-accelerate the muons to their original momentum. If the scattering in the absorbing medium is not too large, the reaccelerated muon beam will have a lower emittance than the muon beam that entered the absorbers. The MICE cooling channel cools the muons and reaccelerates them to their original energy.

This report describes the tracker module that used to measure the muon emittance entering and leaving the MICE cooling channel. The superconducting tracker solenoid is the heart of the tracker module.

Manuscript received 29 August 2006. M. A. Green MAGreen@1bl.gov and S. P. Virostek are from the Lawrence Berkeley National Laboratory, Berkeley CA 94720 USA. J. Chen, T. Juang, C. Taylor, R Wahrer and S. T. Wang are from Wang NMR Livermore CA, 94550 USA. W. W. Lau, H. Witte, and S. Q. Yang are from the Oxford University Physics Department, Oxford OX1-3RH, UK. *This work was supported by the Office of Science, United States Department of Energy, under DOE contract DE-AC0205CH11231. DOE funding for the US Neutrino Factory and Muon Collider Collaboration is gratefully acknowledged.

\section{THE MUON IONIZATION COOLING EXPERIMENT}

MICE will test muon cooling using a low intensity muon beam generated from the ISIS ring at the Rutherford Appleton Laboratory in the United Kingdom. MICE is divided into two sections; a muon beam production section and the MICE channel.

Dipping a metal target into the halo of the ISIS proton beam produces pions. The pions will decay into a welldefined muon beam within a 5-meter long decay solenoid. These muons will be carried into the experimental hall by a conventional beam transport system.

The beam enters the MICE channel by passing through a diffuser that will scatter the muons (impart transverse momentum as well as momentum spread) to produce a beam of desired emittance. The entering muon beam emittance will be measured by five planes of scintillating fiber detectors that are in a uniform solenoidal magnetic field at $4 \mathrm{~T}$. Fig. 1 shows schematic view of MICE. Fig. 1 shows the cooling channel and the two trackers at both ends of the experiment.

Once the emittance of the muon beam entering the cooling section has been measured by the first tracker module, the beam passes through an absorber in the first absorber focus coil module (AFC module) that cools the muon beam by ionization cooling. The absorber is in a high magnetic region where the field either goes through zero to the opposite polarity or remains reasonably uniform (depending on which cooling mode is being tested). In either case, the beam beta is supposed to be minimized in the absorber. The MICE test absorbers may be liquid hydrogen, liquid helium, beryllium, plastic, or aluminum. The absorber is surrounded by a twocoil solenoid that produces a uniform field or a cusp field that flips as one goes along the axis [3].

The muon beam momentum is recovered in the RF coupling coil module (RFCC module) [4] by accelerating the beam with a four cell $201.25 \mathrm{MHz}$ RF cavities that are within the coupling magnet 2.0 to $2.5 \mathrm{~T}$ field [5]. After the muon beam has been re-accelerated, it passes through a second AFC module. The process of re-acceleration is repeated in the second RFCC module then the beam passes through the final AFC module. At this point, the beam cooling can be clearly measured.

Once the beam has passed through the MICE cooling section, it enters the second tracker module, which identical to the first tracker module. There is a time of flight TOF detector and a Cherenkov counter calorimeter end of the experiment after the last tracker module. This report presents the basic design parameters for the two tracker magnet modules for MICE. These modules are located at the ends of the MICE channel shown in Fig. 1. 


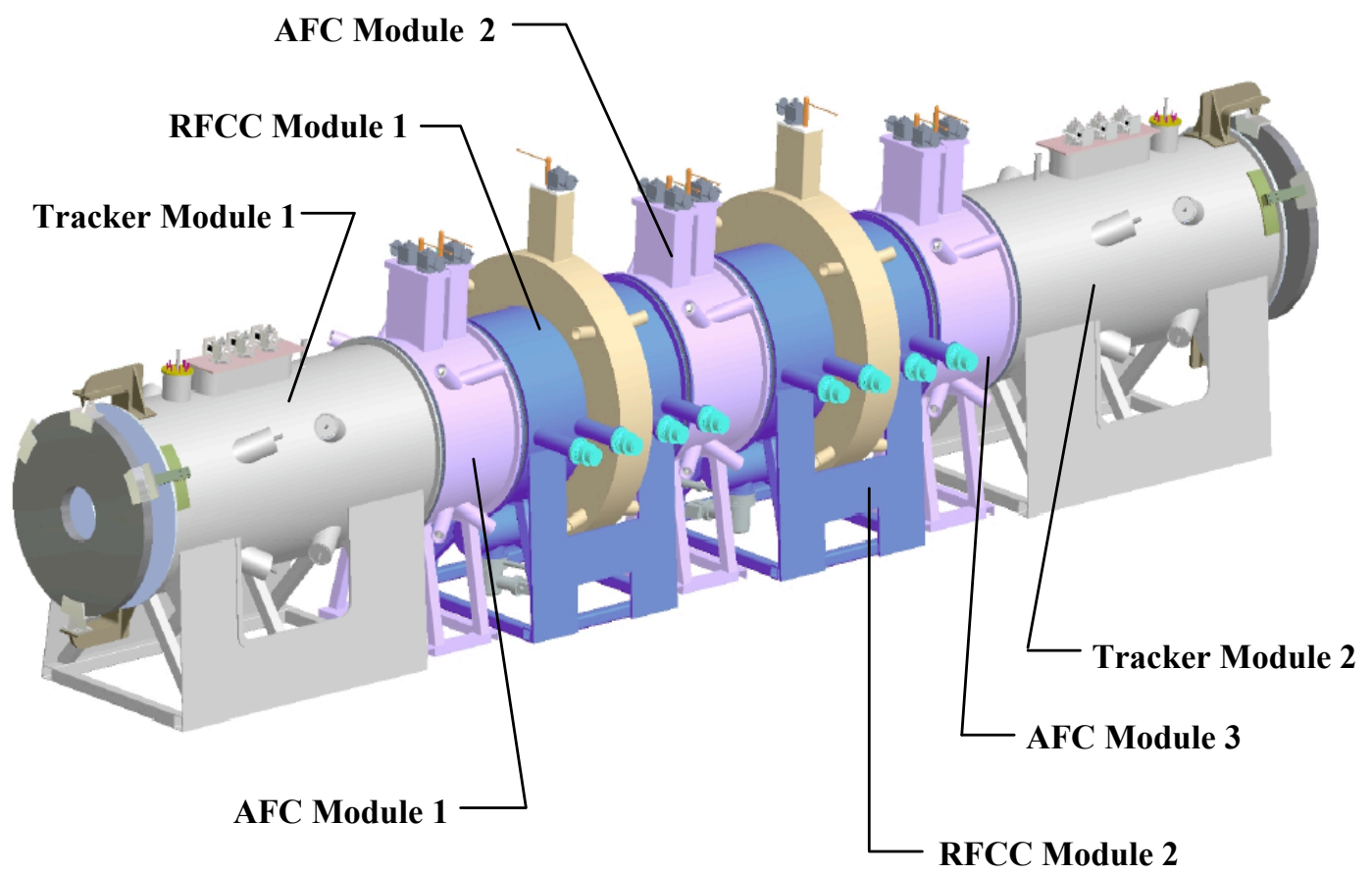

Fig. 1. A Three Dimensional Schematic Representation of the MICE Channel.

\section{THE TRACKER MODULE FOR MICE}

The tracker module consists of a five-coil superconducting solenoid, a magnet cryostat vacuum vessel, a vacuum vessel (MICE vacuum) that contains the radiation shutter, a fiveplane scintillating fiber tracker that operates in a helium atmosphere, a thin window between the MICE vacuum and the tracker atmosphere, a patch panel that carries the light fibers from the trackers to PID cryostat, a window between the tracker volume and the outside world (a muon diffuser in the upstream tracker module), and an iron shield that shields the photo multiplier tubes (PMTs) from the tracker magnet stray field. The PMTs are part of the TOF detector that is located $\sim 500 \mathrm{~mm}$ from the last coil of the tracker magnet.

The radiation shield between the AFC module and the tracker magnet, which is like a shutter, is the equivalent to $50-\mathrm{mm}$. of lead. This shield is used to protect the scintillating fiber detectors that are located in the uniform field region of the detector solenoid, while the RF cavities are being conditioned at high acceleration gradients. During the cavity conditioning process, the RF cavities produce electrons and $\mathrm{x}$-rays that damage the plastic fibers. The radiation shield is open during MICE operation.

The tracker system iron magnetic shield, which is at the end away from the cooling channel, consists of more than one iron ring, which are $1500-\mathrm{mm}$ in outside diameter, with a hole around the axis of the experiment that is $500-\mathrm{mm}$ in diameter. Because the position of the PMT with respect to the TOF detector is very important, the iron shield must be 400 $\mathrm{mm}$ from the last coil of the tracker solenoid. At that distance, the shield will exert an $87 \mathrm{kN}$ longitudinal force (toward the iron) on the magnet coils. This force is smaller than the cold mass support design force of $500 \mathrm{kN}$ [5].

\section{THE TRACKer Magnet}

The tracker magnet consists of two parts. The first section is the uniform field spectrometer solenoid that consists of a single 1290-mm long center coil with two $110-\mathrm{mm}$ long end coils. The field uniformity is \pm 0.5 percent over a 1 -meter long section that is 0.3 meters in diameter at the center spectrometer magnet section. The second section of the tracker solenoid consists of a pair of coils that matches the muon beam from the AFC magnet to the spectrometer solenoid. The five coils are wound on a common mandrel, so that the longitudinal magnetic forces can be carried along the solenoid. The maximum inter-coil longitudinal force in the magnet is about $1370 \mathrm{kN}$ (140 tons) from the end coil near the iron shield to the center coil of the detector set.

The three spectrometer coils will be connected in series with one pair of $300 \mathrm{~A}$ leads connected to the outside world. Each of the match coils has its own pair of 300 A current leads. There is a pair of $50 \mathrm{~A}$ current leads across the center coil of the detector magnet that permits each of the end coils to be separately tuned so that the effect of the iron shield can be minimized and so that the tuning process between the AFC module and the tracker module can be optimized.

The tracker module length is $\sim 2923 \mathrm{~mm}$ long. The magnet cryostat vacuum vessel length is $\sim 2735 \mathrm{~mm}$. The magnet warm bore is $400 \mathrm{~mm}$. The outer diameter of the tracker module is about $1404 \mathrm{~mm}$. The length of the cold mass is $2554 \mathrm{~mm}$. The cold mass inner diameter will be $490 \mathrm{~mm}$ and outer diameter will be about $724 \mathrm{~mm}$. The tracker magnet cold mass will be $\sim 2100 \mathrm{~kg}$. The overall mass of the tracker module will be $\sim 5000 \mathrm{~kg}$ when the iron shield is attached. The detector magnet parameters are shown in Table 1. 
TAble 1. The Nominal Design Parameters for the MiCE Tracker Solenoid Coils

\begin{tabular}{lccccc}
\hline \multicolumn{1}{c}{ Parameter } & Match 1 & Match 2 & End 1 & Center & End 2 \\
\hline Inner Coil Radius (mm) & 258 & 258 & 258 & 258 & 258 \\
Coil Thickness (mm) & 44.6 & 29.8 & 59.6 & 21.3 & 63.9 \\
Coil Length (mm) & 201.2 & 199.5 & 110.6 & 1314.3 & 110.6 \\
Current Center Axial Position* (mm) & 3611.0 & 4051.5 & 4451.0 & 5201.0 & 5952.0 \\
Current Center Radial Position* (mm) $_{\text {Coil Average J (A mm }{ }^{-2} \text { ) }}$ & 280.4 & 272.9 & 287.8 & 268.7 & 289.9 \\
Number of layers per Coil & 142.19 & 152.62 & 133.28 & 153.38 & 141.95 \\
Number of Turns per Layer & 42 & 28 & 56 & 20 & 60 \\
Design Current (A)** & 120 & 119 & 66 & 784 & 66 \\
Coil Self Inductance (H)^ & 253.8 & 273.6 & 226.6 & 269.9 & 240.7 \\
Coil Stored Energy (MJ)** & 13.0 & 5.4 & 9.5 & 41.4 & 11.1 \\
Peak Field in Coil (T)** & 0.42 & 0.20 & 0.26 & 1.54 & 0.32 \\
Temperature Margin at 4.2 K (K)** & 5.30 & 4.32 & 5.68 & 4.24 & 5.86 \\
Conductor Length (m) & $\sim 1.7$ & $\sim 1.9$ & $\sim 1.6$ & $\sim 2.0$ & $\sim 1.5$ \\
Coil Mass (kg) & 8880 & 5714 & 6684 & 26473 & 7215 \\
\hline \hline
\end{tabular}

* $\mathrm{R}$ and $\mathrm{Z}$ are with respect to the center of MICE (the center of the central AFC magnet). $\mathrm{R}=0$ is the MICE axis.

** For $\mathrm{p}=240 \mathrm{MeV} / \mathrm{c}$ and $\square=42 \mathrm{~cm}$ with the iron shield, based on $300 \mathrm{~K}$ coil dimensions

\section{The Tracker Magnet CoIL Design}

The design of the magnet coils shown in Table 1 is based on $\mathrm{Nb}$-Ti conductor with a copper matrix, which has bare dimensions of $0.95 \mathrm{~mm}$ by $1.60 \mathrm{~mm}$. The insulated dimensions are about $1.00 \mathrm{~mm}$ by $1.65 \mathrm{~mm}$. The conductor insulation is a layer of Formvar that is about $0.025 \mathrm{~mm}$ thick. The conductor corners are rounded to prevent insulation cracking. The number of layers in each coil is even because one wants the coil leads come out at the same end and one wants to minimize the effects of the winding pitch on the field quality. The tracker magnet conductor is $3.9 \pm 0.4$ parts copper to 1 part Nb-Ni. The design conductor twist pitch is $19 \mathrm{~mm}$. The conductor has 222 filaments that are approximately 41 $\square \mathrm{m}$ in average diameter. The conductor $\mathrm{I}_{\mathrm{c}}=760 \mathrm{~A}$ at $5 \mathrm{~T}$ and $4.2 \mathrm{~K}$. The two tracker solenoids will be wound with $109 \mathrm{~km}$ of conductor purchased from Outkompu in Waterbury $\mathrm{CN}$ in the United States. The conductor was delivered in six lengths ranging from $5 \mathrm{~km}$ to $33 \mathrm{~km}$. A cross-section of the tracker magnet conductor is shown in Figure 2. The turns per layer and layer thickness $(\sim 1.065 \mathrm{~mm})$ for the coils shown in Table 1 assume that the conductor is wound with the long dimension parallel to the solenoid axis.

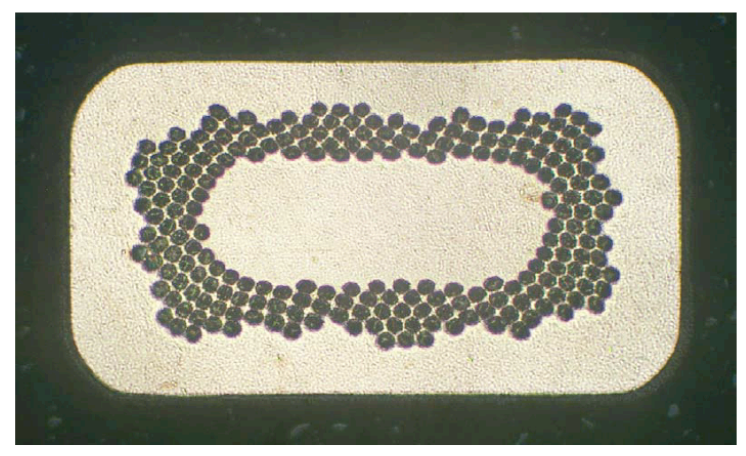

Fig. 2. Magnet Conductor Cross-section with $222 \mathrm{Nb}$-Ti Filaments in a Copper Matrix $\left(I_{c}=760\right.$ A @ 95 T \& $4.2 \mathrm{~K}$.

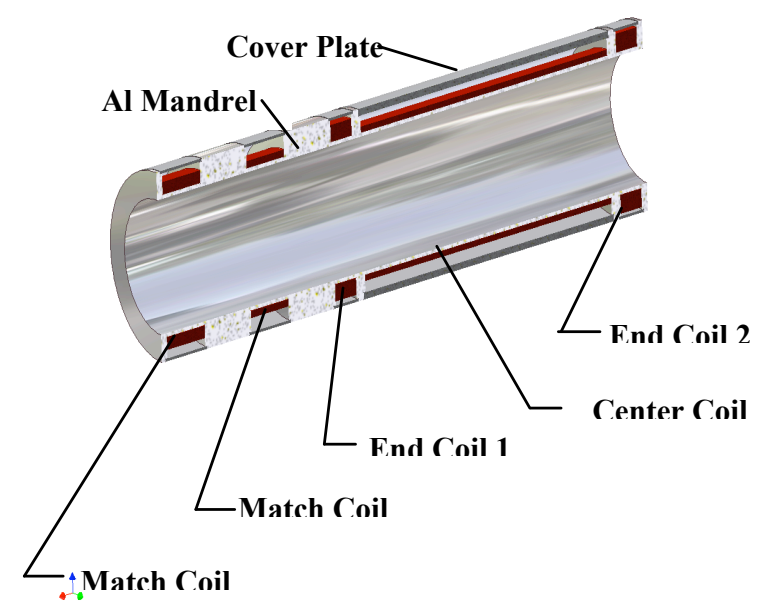

Fig. 3. A 3 D View of the Tracker Solenoid Cold Mass.

The cold mass of the tracker solenoid is shown in Fig. 3. The superconducting coils will be wound on a forged 6061aluminum mandrel. The mandrel and the cover plate carry the longitudinal forces within the cold mass. There is aluminum banding on the outside of the coils. The space between the banding and the cold mass cover plates will contain about 190 liters of liquid helium and the quench protection diodes. The tracker magnet will be kept cold with two or three $1.5 \mathrm{~W}$ coolers. The connection between the $4 \mathrm{~K}$ second stage of the coolers and the magnet cold mass is through thermal siphon heat pipes [7].

The design of the tracker solenoid is conservative. The stress within the coils and the aluminum spacers is well below the yield stress of the materials in the coil package. Since the detector magnet design is quite conservative, the temperature margin in the magnet is high $(>1.4 \mathrm{~K}$ at $4.2 \mathrm{~K})$ for all of the coils. The extra temperature margin may permit the tracker solenoid to operate with two coolers. Figure 4 shows the magnet load lines and the conductor Ic for the five tracker solenoid coils. The coil temperature margin is illustrated in Fig 4 as well as Table 2. 


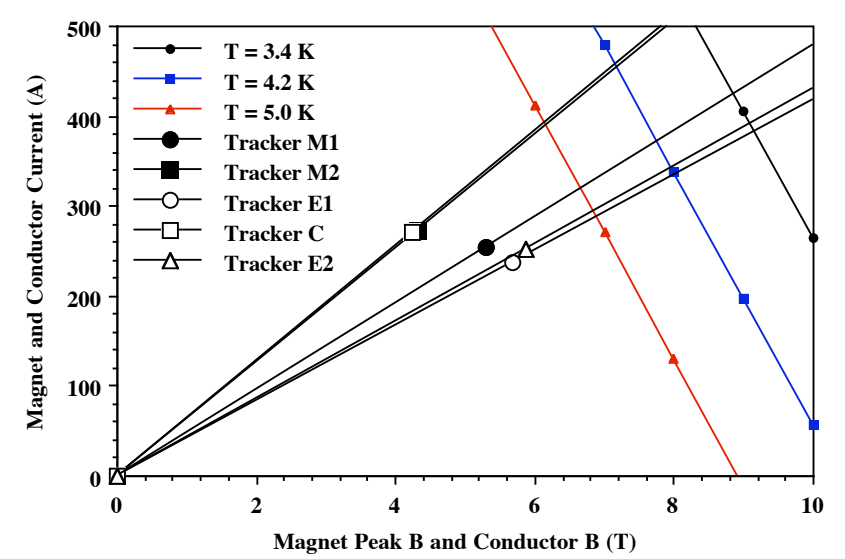

Fig. 4. The Load Lines for the Five Tracker Coils and the $\mathrm{I}_{\mathrm{C}}$ versus $\mathrm{T}$ for the Tracker Magnet Superconductor.

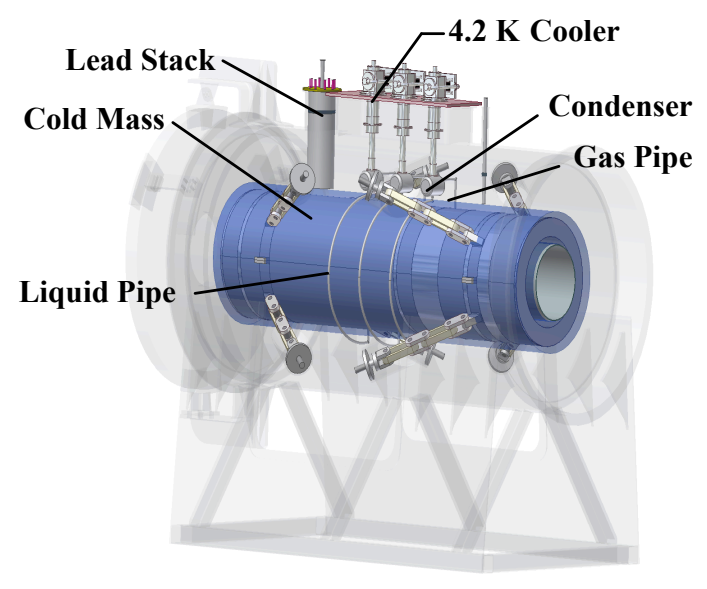

Fig. 5. The Connection of the $1.5 \mathrm{~W}$ Coolers to the Tracker Magnet Cold Mass as well a The Magnet Cold Mass Supports.

\section{CoOling The Magnet with SMall CoOlers}

Figure 5 shows the tracker magnet cold mass, the cold mass supports and the connection between three coolers and the cold mass. The cold mass supports for the magnet are designed for a maximum longitudinal force of $500 \mathrm{kN}$. The heat leak into the cooler first stage is dominated by the heat leak down three pairs of $300 \mathrm{~A}$ copper leads and a pair $50 \mathrm{~A}$ copper leads. The radiation heat load and conduction heat load into the cooler first stage are much lower. The heat leaks into the $4 \mathrm{~K}$ region is dominated by heat leaks down the HTS leads that connect from the cooler first stage to $4 \mathrm{~K}$. The cold mass support heat leaks and radiation heat leaks are lower. The heat loads shown in Table 2 suggest that only two coolers may be needed to cool the tracker magnet.

TAble 2. Estimated Heat LoAds at $60 \mathrm{~K}$ AND $4.2 \mathrm{~K}$

\begin{tabular}{lcc}
\hline \multicolumn{1}{c}{ Component } & \multicolumn{2}{c}{ Heat Leak (W) } \\
& $@ 60 \mathrm{~K}$ & $@$ @ $4 \mathrm{~K}$ \\
\hline Cold Mass Supports & $\sim 7$ & 0.31 \\
Radiation through MLI & $\sim 11$ & $\sim 0.4$ \\
Necks and Instrumentation & $\sim 11$ & $\sim 0.55$ \\
Current Leads & $\sim 80$ & 1.05 \\
Total Estimated Heat Leak & $\sim 109$ & $\sim 2.31$ \\
\hline \hline
\end{tabular}

There are two types of coolers commercially available for cooling the magnets. These are Gifford McMahon (GM) coolers and pulse tube coolers with a thermodynamic cycle similar to that of a GM cooler. $1.5 \mathrm{~W}$ coolers of both types are available. The critical selection issue for the MICE magnet coolers is the stray magnetic field around the magnets. The MICE doesn't have an iron shield to return the magnetic flux and shield the coolers. GM coolers are sensitive to magnetic field at cold pistons and at the drive motor on the top of the cooler. Magnetic field can cause excessive wear in the cooler cold heads and it can cause the motor to stall. Both are a problem when the magnetic field is $>0.08 \mathrm{~T}$. A pulse tube cooler is sensitive to magnetic field $>0.08 \mathrm{~T}$ in the rotary valve motor that creates the pulses for the pulse tubes. An advantage of the pulse tube cooler is the fact that this motor can be located remotely away from the cold head, where the magnetic field is much lower.

The magnetic field in the region where the coolers will be located on the tracker solenoid is about $0.15 \mathrm{~T}$ on the second stage cold head and $\sim 0.06 \mathrm{~T}$ at the location of the drive motor (or $\sim 0.04 \mathrm{~T}$ at the pulse tube cooler valve motor). As a result, pulse tube coolers have been tentatively selected for the tracker solenoids. It is proposed that two $1.5 \mathrm{~W}$ coolers be used on each tracker magnet. Space for a third cooler will be provided on the tracker magnet cryostat.

\section{CONCLUDING COMMENTS}

The superconducting tracker magnets for MICE can be built with existing niobium titanium conductors. There is enough margin in the detector magnet design to allow for tuning of the MICE magnets and still have reasonably large temperature margins for each of the detector coils. The forces within the magnet can he handled by the proposed coil and aluminum spacer structure.

The detector solenoid can be cooled using two pulse tube coolers. A key factor in using small coolers to cool the tracker magnet is maintaining a low temperature difference between the magnet hot spot and the cooler cold heads. This temperature difference can be less than $0.2 \mathrm{~K}$

\section{REFERENCES}

[1] R. B. Palmer, A. Sessler, A. Skrinsky, A. Tollestrup, et al, "Muon Colliders, " Brookhaven National Laboratory Report BNL-62740, January 1996

[2] G. Gregoire, G. Ryckewaert, L. Chevalier, et al, "MICE and International Muon Ionization Cooling Experiment Technical Reference Document," http://hep04.phys.itt.edu/cooldemo

[3] S. Q. Yang, M. A. Green, et al, "The Mechanical and Thermal Design for the MICE Focusing Solenoid Magnet System," IEEE Transactions on Applied Superconductivity 15, No. 2, p 1259, (2005).

[4] D. Li, M. A. Green, S. Virostek, and M. S. Zisman, "Progress of the RF coupling Module for the MICE Channel," Proceedings of 2005 Particle Accelerator Conference Knoxville TN, p 3417, (2005)

[5] M. A. Green, S. Q. Yang, et al, "The Mechanical and Thermal Design for the MICE Coupling Solenoid Magnet," IEEE Transactions on Applied Superconductivity 15, No.2, p 1279, (2005).

[6] S. Q. Yang, D. E. Baynham, P. Fabricatore, et al, "The Physical Connection and Magnetic Coupling of the MICE Cooling Channel Magnets and the Magnetic Forces for Various Operating Modes," IEEE Transactions on Applied Superconductivity 17, (this volume), (2007)

[7] M. A. Green, "How the Performance of a Superconducting Magnet is affected by the Connection between a Small Cooler and the Magnet," IEEE Transactions on Applied Superconductivity 16, No. 1, p 1330, (2006). 


\section{DISCLAIMER}

This document was prepared as an account of work sponsored by the United States Government. While this document is believed to contain correct information, neither the United States Government nor any agency thereof, nor The Regents of the University of California, nor any of their employees, makes any warranty, express or implied, or assumes any legal responsibility for the accuracy, completeness, or usefulness of any information, apparatus, product, or process disclosed, or represents that its use would not infringe privately owned rights. Reference herein to any specific commercial product, process, or service by its trade name, trademark, manufacturer, or otherwise, does not necessarily constitute or imply its endorsement, recommendation, or favoring by the United States Government or any agency thereof, or The Regents of the University of California. The views and opinions of authors expressed herein do not necessarily state or reflect those of the United States Government or any agency thereof, or The Regents of the University of California. 